Article

\title{
Analytical Models and Laboratory Measurements to Explore the Potential of GPR for Quality Control of Marble Block Repair through Resin Injections
}

\author{
Marjan Izadi-Yazdanabadi ${ }^{1}$ (D), Azadeh Hojat ${ }^{1,2, *(D)}$, Luigi Zanzi ${ }^{2, *(\mathbb{D})}$, Saeed Karimi-Nasab ${ }^{1}$ (D) \\ and Diego Arosio ${ }^{3}$ (D)
}

1 Department of Mining Engineering, Shahid Bahonar University of Kerman, Kerman 76188, Iran; marjaniz326@gmail.com (M.I.-Y.); kariminasab@uk.ac.ir (S.K.-N.)

2 Dipartimento di Ingegneria Civile e Ambientale, Politecnico di Milano, 20133 Milan, Italy

3 Dipartimento di Scienze Chimiche e Geologiche, Università degli Studi di Modena e Reggio Emilia, 41125 Modena, Italy; diego.arosio@unimore.it

* Correspondence: ahojat@uk.ac.ir or azadeh.hojat@polimi.it (A.H.); luigi.zanzi@polimi.it (L.Z.)

\section{check for}

updates

Citation: Izadi-Yazdanabadi, M.;

Hojat, A.; Zanzi, L.; Karimi-Nasab, S.;

Arosio, D. Analytical Models and

Laboratory Measurements to Explore

the Potential of GPR for Quality

Control of Marble Block Repair

through Resin Injections. Appl. Sci.

2022, 12, 987. https://doi.org/

10.3390/app12030987

Academic Editors: Adriano Ribolini

and Forte Emanuele

Received: 26 December 2021

Accepted: 17 January 2022

Published: 19 January 2022

Publisher's Note: MDPI stays neutral with regard to jurisdictional claims in published maps and institutional affiliations.

Copyright: (c) 2022 by the authors. Licensee MDPI, Basel, Switzerland. This article is an open access article distributed under the terms and conditions of the Creative Commons Attribution (CC BY) license (https:/ / creativecommons.org/licenses/by/ $4.0 /)$.

\begin{abstract}
This work aims to analyze theoretically and with laboratory tests the sensitivity of highfrequency GPR (Ground-Penetrating Radar) to resin injections used in the building and ornamental stone industries to repair marble blocks before final slab cutting. We simulate uniform fractures in the laboratory using small regular marble blocks and we compare the results of GPR tests with the analytical model of the thin bed reflections. We performed two series of GPR surveys with a $3 \mathrm{GHz}$ antenna, progressively increasing the fracture thickness from $0.25 \mathrm{~mm}$ to $16 \mathrm{~mm}$, to analyze the results on two simulated conditions: open fracture and repaired fracture. The repaired condition was simulated by substituting the resin layer with polyvinyl chloride (PVC) sheets because the permittivity of PVC is quite similar to the permittivity of epoxy resin. According to the analytical models, when a thin air-filled fracture is filled with resin, the received signal amplitude is expected to decrease by $33 \%$ ( $26 \%$ if resin is simulated with PVC). The results showed a very good match between the predictions and the real data observations when the fracture is thicker than $4 \mathrm{~mm}$. Although the analytical and laboratory results show some deviations when the fracture is thinner than $4 \mathrm{~mm}$, the qualitative trend of the amplitude variations is still consistent with the predictions and the $3 \mathrm{GHz}$ antenna can resolve the change in the filling material down to the minimum tested thickness $(0.25 \mathrm{~mm})$. As a result, our findings validate the GPR method as a proper tool for nondestructive quality control of resin injections in marble fractures.
\end{abstract}

Keywords: marble; building stones; fractures; resin injections; ground penetrating radar; thin bed reflection; analytical models; nondestructive testing; quality control

\section{Introduction}

Discontinuities and defects of natural building stones have always concerned quarry engineers and experts engaged in the restoration and conservation of stone monuments. Fractures and voids are also a critical problem when the natural stone is supposed to be used for decorative and ornamental purposes. In recent years, there has been an increasing interest in repairing natural stones by injecting a filling material in their fractures. Nondestructive methods are then required to monitor the injection efficiency. Therefore, after detecting the fractures and voids, defects can be filled in order to improve the quality of stones. A common solution is to inject a filling material such as different polyester resins, epoxy resins, or cement in some cases [1,2]. The properties and good performance of epoxy resin in this field have introduced it as a practical filling material [3-6]. However, successful repair of stones using filling materials depends on deep penetration of the injected material and optimum filling of the fractures. Thus, the quality check of the injection operation 
with a nondestructive method is of primary importance to validate the success of the repair operation.

Geophysical surveys have always played an important role in different projects that concern natural resources. Wherever high contrasts in the physical properties of the target and its hosting medium are expected, proper geophysical techniques can be successfully applied to provide valuable information about the subsurface conditions, e.g., [7-18]. Among different geophysical techniques, the ground penetrating radar (GPR) method can provide high-resolution results in a variety of applications, e.g., [19-33]. In recent decades, GPR surveys have been increasingly used in the quarrying industry and stone production to study the depth to different layers, detect faults and fractures and monitor the defects of stones, e.g., [11,13,34-43]. Considering the high potential of the GPR method to enter the quarrying and stone industry, interest is increasing in studying the capabilities of the GPR method to help in different stages of stone production.

The need to investigate the effectiveness of the GPR technique for characterizing fractures and determining their aperture and filling material emerged in the last decade and the research is still ongoing [40,42]. The GPR method has the potential to detect the fractures of stones and monitor their repair conditions to help in optimal production of building stones as well as managing the repair or protection of stones in use. Previous studies have demonstrated the sensitivity of high-frequency GPR antennas to fracture aperture and to different properties of the material hosted within the fractures $[44,45]$. However, the objective of these studies was to explore the potential of GPR as a tool for characterizing a fractured rock by determining fracture apertures and hosted materials (e.g., water, clay, sand, air). The main conclusion of these studies is that the GPR method has the required sensitivity, but fracture aperture and hosted material are conflicting properties that can be hardly distinguished in field conditions unless strong a priori assumptions can be made to reduce the spectrum of possible materials present in the fractures. Moreover, a complex procedure in the frequency domain is implemented by considering not only the amplitude response of the radar wave but also the phase response [46]. In this paper, we focus our attention on the specific objective of resin-injection quality control. As a result, we reduce the range of possible filling materials to either completely filled with air or completely filled with resin. Under this assumption, we analyze the amplitude difference in GPR data before and after resin injection in fractures of marble blocks. The results are promising for a practical application in a real environment, showing the capability of GPR measurements to help the quarrying industry to produce higher quality stones for building or ornamental use.

\section{Materials and Methods}

Rock fractures can be considered thin layers in a homogeneous rock from the GPR point of view [47]. In this study, we used the analytical model of thin bed to calculate the theoretical expectation for GPR measurements before and after resin injection. Our studies are limited to the assumption that the fractures are filled first with air and then with resin. We then performed GPR measurements on marble blocks with uniform fractures before (filled with the air) and after repair (filled with the resin), to explore how GPR data will be really affected after resin injection. In order to avoid superposition of the desired reflections by the reflections from the sides of the blocks, a test was performed to determine the proper dimensions for the blocks to be used in laboratory tests.

Four marble blocks from a quarry in Botticino, Italy, were used for laboratory experiments. The contact between two blocks was used to simulate the air-filled fracture, increasing the fracture aperture progressively. These fractures were then filled with resin sheets to compare GPR results of air-filled fractures with those being repaired by resin injection. Since our lab facilities cannot guarantee the required accuracy in producing resin sheets with very thin thickness (lower than $1 \mathrm{~mm}$ ) and the production of resin sheets is time-consuming, we decided to test only two different apertures $(1 \mathrm{~mm}$ and $2 \mathrm{~mm}$ ) with resin-filled fractures. To test the procedure on a wider range of apertures (from $0.25 \mathrm{~mm}$ to 
$16 \mathrm{~mm}$ ), we simulated the resin material with industrially produced uniform sheets made from polyvinyl chloride (PVC) with permittivity values close to those of the epoxy resin. We used an IDS antenna with the frequency of $3 \mathrm{GHz}$ in all experiments [48]. Amplitude differences observed in our measurements, even though the difference is not exactly equal to the theoretical prediction for some fracture apertures, prove the capability of the GPR method to monitor the repair of stones.

\subsection{Selecting the Dimensions of the Blocks}

In order to select the dimensions of marble blocks to be used for our laboratory tests, preliminary measurements were performed on a few already-available Carrara marble blocks, quarried in Tuscany in the center of Italy. The velocity of radar waves in these blocks and the relative permittivity were, respectively, $0.096 \mathrm{~m} / \mathrm{ns}$ and 9.63, as measured in some previous studies [40]. The dimensions of these blocks were $75 \times 60 \times 21 \mathrm{~cm}$, and being too heavy, it was not possible to move them without the use of a small laboratory hoist. Therefore, we decided to select smaller blocks that we could manage to move as much as required for our current study.

The $3 \mathrm{GHz}$ antenna that was used for all our experiments was also used for the survey to determine the block dimensions. Figure 1a illustrates the data acquisition procedure that was based on time triggering of the antenna with its position fixed on the top block in the center. A $5 \mathrm{~mm}$-thick high-density polyethylene (HDPE) layer was placed between the two blocks. Figure $1 \mathrm{~b}$ shows the GPR data after applying time calibration and dewow. The vertical axis is the two-way reflection time, and the horizontal axis is the number of the collected traces because the antenna was placed in the center of the block and was continuously collecting data at regular time intervals. Figure $1 \mathrm{c}$ shows a single radar trace extracted from Figure $1 \mathrm{~b}$ and plotted in wiggle mode to better compare the amplitudes of the recorded events. We can easily recognize the reflection from the thin bed, i.e., the boundary between the two blocks, at $4-4.5 \mathrm{~ns}$ (red arrow). The reflection is well-isolated from other events because the reflections generated by the surface waves reflected from the edges of the block and/or the multiples of the thin bed reflection arrive later than $6.5 \mathrm{~ns}$ and they are quite weak (blue arrows). Moreover, $4 \mathrm{~ns}$ are more than enough to separate the arrival of the thin bed reflection from the weak horizontal reverberations of the background signal which do not last more than 2 ns. Based on these data, we can predict that by reducing the thickness of the marble blocks to $10 \mathrm{~cm}$, we still preserve the necessary separation, about $2 \mathrm{~ns}$, between the background signal and the thin bed reflection as well as between the thin bed reflection and its multiples. To ensure that surface wave reflections from the block edges also arrive later and with a similar delay of about $2 \mathrm{~ns}$, the distance between the antenna and block edges has to be larger than $20 \mathrm{~cm}$. In conclusion, we selected the ideal size of $40 \times 40 \times 10 \mathrm{~cm}$ for the marble blocks to be used, expecting the weight of each block to be about $42 \mathrm{~kg}$.

Therefore, four uniform marble blocks were extracted with the desired dimensions from Botticino Classico rocks, the quarries in Botticino in the province of Brescia, the second most momentous quarrying area in Italy [49]. Figure 2 demonstrates an example of the GPR measurements performed using three of these blocks with their contacts considered as the air-filled fractures. We remind that all our GPR measurements were performed using a $3 \mathrm{GHz}$ IDS antenna fixed in the center of the blocks. All GPR data acquisitions of this study were time-triggered.

\subsection{Laboratory Measurements}

The contact between the two upper marble blocks of the block pile was considered as the objective fracture. The fracture aperture (thickness of the contact) was gradually increased to study GPR response for different fracture apertures. GPR measurements were first performed on the blocks with air-filled fractures. Then, filling materials with the same thickness range of air-filled fractures were put in the contact between the blocks and GPR 
measurements were repeated for each thickness. Epoxy resin and PVC sheets were the filling materials used in this study.

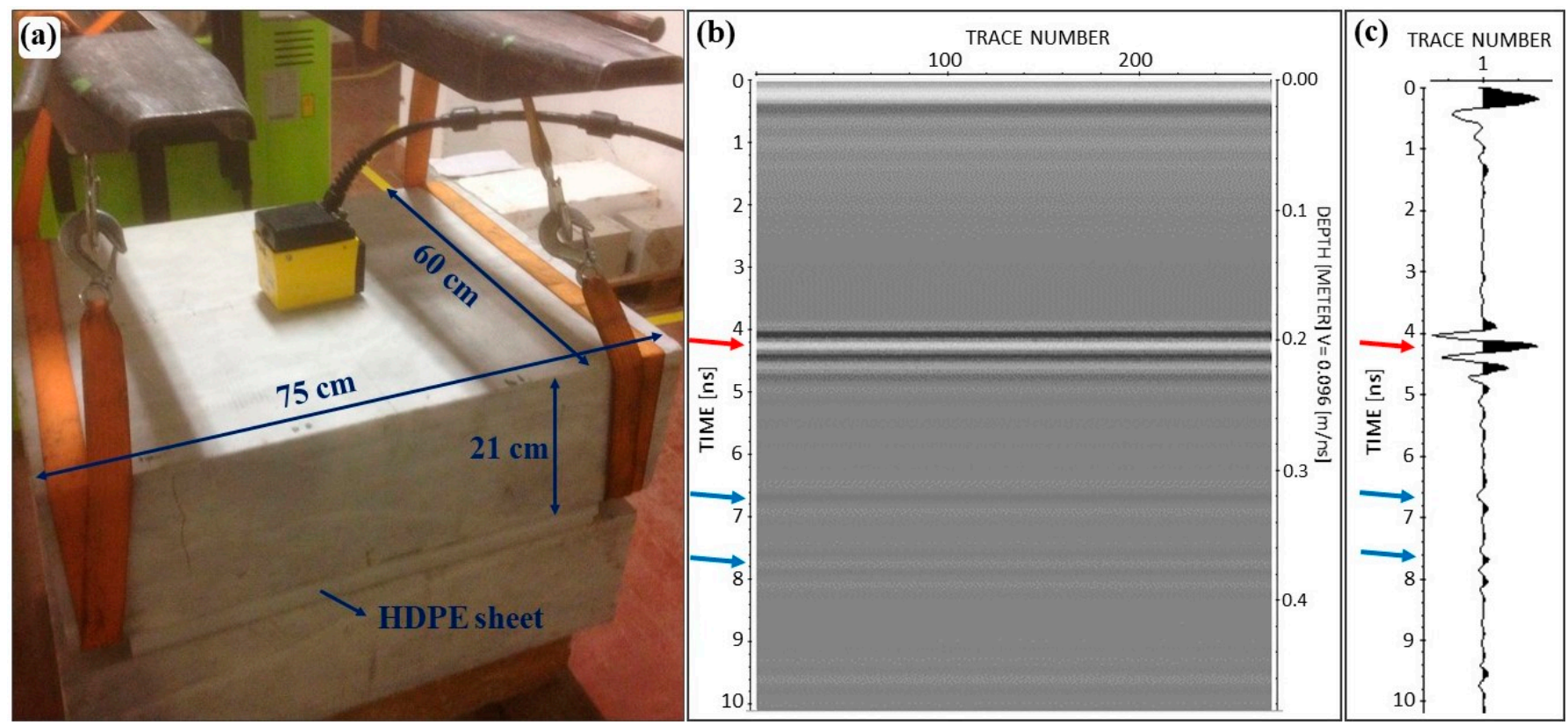

Figure 1. (a) Time-triggered GPR data acquisitions on two marble blocks separated with an HDPE layer. (b) The processed GPR data. (c) A single radar trace extracted from the processed GPR data.

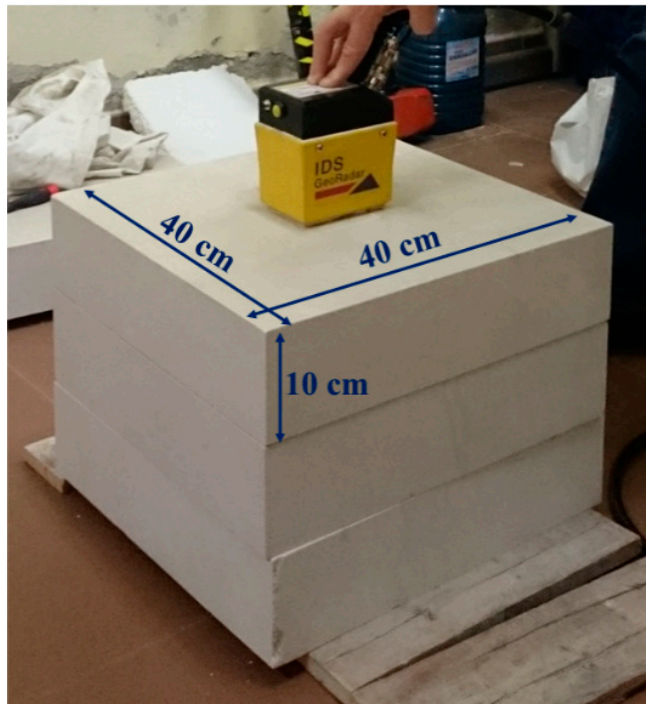

Figure 2. Time-triggered GPR measurements with the antenna fixed in the center of the marble blocks.

\subsubsection{Filling Material}

The epoxy resin (Figure 3a) used in this research is a transparent epoxy resin that consists of two components: resin (density: $1.12 \mathrm{~g} / \mathrm{cm}^{3}$; mass fraction: 5/8) and hardener (density: $0.98 \mathrm{~g} / \mathrm{cm}^{3}$; mass fraction: $3 / 8$ ). The main properties of this epoxy resin are excellent mechanical strength, good chemical resistance, extended workability, excellent environmental moisture resistance and a short catalysis time $\left(6 \mathrm{~h}\right.$ for $1 \mathrm{~mm}$ sheet at $\left.30{ }^{\circ} \mathrm{C}\right)$. The low viscosity of this epoxy resin prevents the air bubbles to remain after hardening. It also allows the epoxy resin to penetrate deep into rock cracks and fractures to be uniform after drying [50]. Considering that we used the contacts between the blocks for simulating the fractures in the lab and we aimed at studying a variety of fracture apertures, we did not inject resin in the fractures. Instead, the repair after resin drying was simulated by 
first preparing the dried resin layers and then putting them in the fractures. This way, we ensure that the same blocks could be used in all measurements, keeping the condition of the blocks unchanged. Figure 3 a demonstrates the steps we followed to prepare a couple of resin layers, each with the thickness of $1 \mathrm{~mm}$. After calculating the volume of resin required for a $40 \times 40 \times 0.1 \mathrm{~cm}$ layer, proper volume percentages of the components $\mathrm{A}$ and $\mathrm{B}$ were mixed (1). To avoid any irregularities, a completely flat base was prepared and covered with a plastic film to prevent the resin from being attached to this base. The side walls of a $40 \times 40 \mathrm{~cm}$ square were prepared using adhesive silicone (2). The required volume of resin was poured on the prepared base, always keeping the base perfectly horizontal to prevent resin from flowing and being accumulated at a corner (3). Considering the objectives of our study, keeping a uniform thickness at different parts of the resin layer was very important. When the resin layer was dried, it was easily detached from the base (4) thanks to the plastic cover below it. The thickness of the resin layer was measured at different parts to control its uniform thickness. To simulate the repaired fractures with the apertures of $1 \mathrm{~mm}$ and $2 \mathrm{~mm}$, one and two epoxy resin sheets were, respectively, placed between the marble blocks. To simulate the repair of larger fracture apertures in an economic way, PVC sheets with the relative permittivity close to the relative permittivity of epoxy resin were used as the filling material (Figure 3b). Another benefit in using PVC material is that, being industrial products, PVC sheets have uniform thickness regardless of how thin they might be. Preparing extremely thin and uniform resin sheets in the laboratory, on the other hand, is very difficult, if not impossible.

According to the information available about the properties of various epoxy resins and PVC material, the relative permittivity of epoxy resin is usually expected to be in the range 3.5-4.7 while the permittivity of PVC is in the range 3-3.3 [51-53]. Thus, the two materials are roughly similar and we expect similar responses to GPR surveys. Additionally, since the permittivity of PVC is a bit lower than the permittivity of epoxy resin, the amplitude comparison of radar response between the air and PVC is expected to be more challenging than the comparison between the air and resin. As a matter of fact, the higher the permittivity of the filling material, the more easily it can be distinguished from the air. Similarly, to make conservative conclusions in the analytical models, we decided to assume the relative permittivity of 3.5 and 3 for epoxy resin and for PVC, respectively, i.e., the lowest values for these materials.

\subsubsection{GPR Measurements}

All GPR measurements were performed in the time-triggered mode, placing the antenna in the center of the upper block (Figure 4a). As shown in Figure $4 \mathrm{a}$, the block above the thin layer was rotated $45^{\circ}$ with respect to the lower blocks. This setup allows easier handling of the upper block, which had to be removed and replaced many times to change the fracture aperture. Prudentially, we performed a test to compare the data before and after rotation of the upper block without observing any difference. As a matter of fact, no artifacts are expected from this modification of the setup because the distance between the antenna and any edge of the first and second marble block is still equal or larger than $20 \mathrm{~cm}$, thus ensuring that no other signals except the thin bed reflection can arrive within the first 3 ns. 

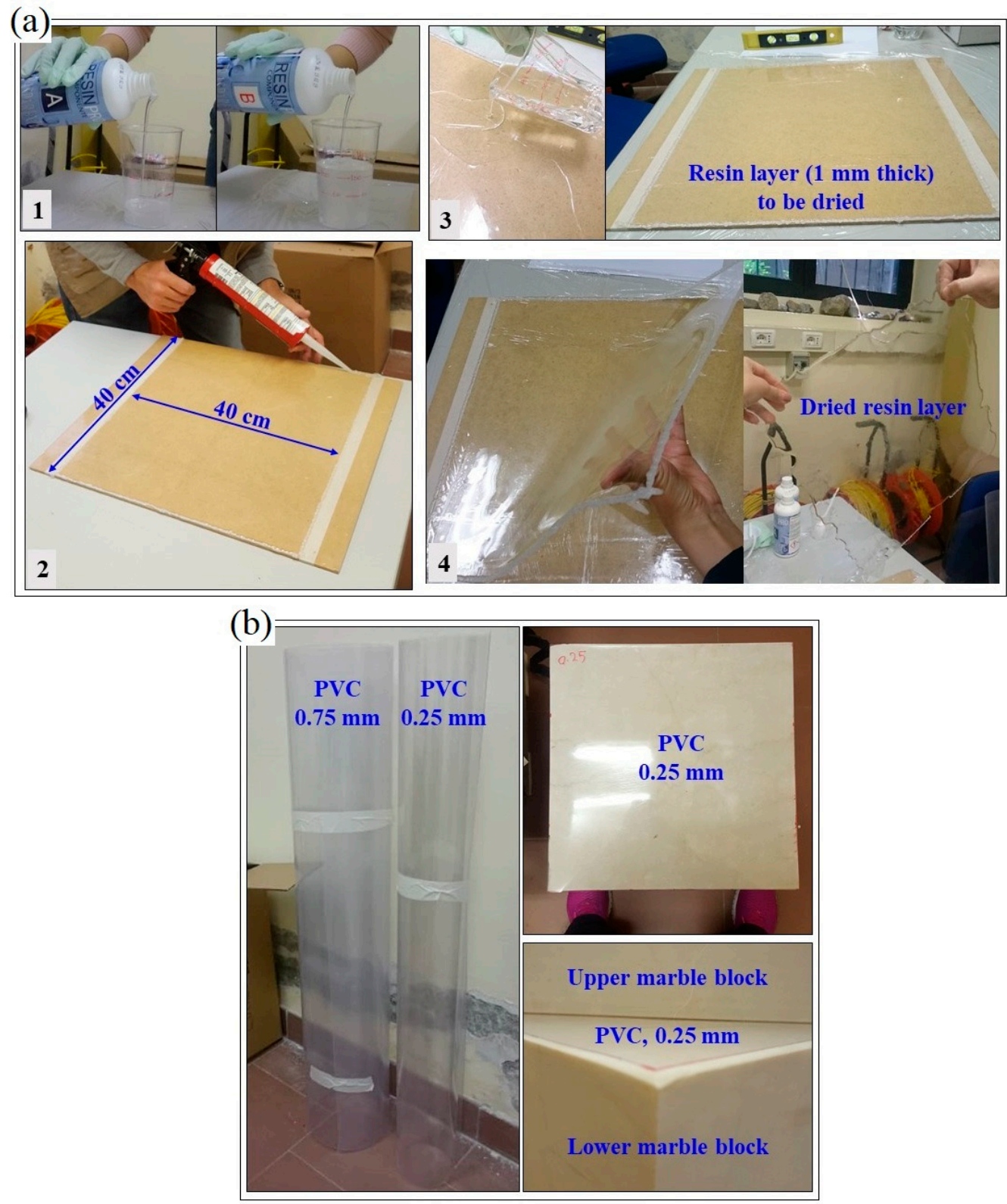

Figure 3. (a) The procedure to prepare resin sheets with the thickness of $1 \mathrm{~mm}$ in the laboratory: 1. Mixing resin components; 2 . Preparing a flat surface covered by a plastic film and adding adhesive silicone side walls; 3. Pouring the volume of resin required to prepare a $40 \times 40 \times 0.1 \mathrm{~cm}$ layer, always keeping the surface horizontal; 4 . Detaching the dried resin layer. (b) PVC material that was used instead of resin in the fractures (block contacts).

At the first step, GPR measurements were designed to calibrate the wave velocity in marble blocks in order to obtain an accurate estimation of the marble permittivity, which is a fundamental parameter to predict the thin bed behavior. In order to estimate the EM wave velocity in the blocks, the antenna was placed on the top block, and a metal shield was placed below it. The test was also performed with all the four blocks (Figure $4 \mathrm{~b})$. A sharp reflection of the shield was observed at the known depth $(10 \mathrm{~cm}$ in the first record and $40 \mathrm{~cm}$ in the second record). The difference between the recorded two-way travel times is an accurate measurement of the time taken by the radar wave to travel forward and backward in $30 \mathrm{~cm}$ of marble material. In principle, this method is better than using only the single block data. The advantage of making two measurements rather than one is that with only one measurement, the result is affected by the accuracy of the time calibration, 
which is always questionable. The background signal is different from the shield reflection and thus we should not use the difference between the background and the reflection for accurate velocity calculation. On the other hand, with two measurements on two different thickness values, the result is not affected by the time calibration. Therefore, we subtracted the time related to the reflection from the shield placed below one block from the time related to the reflection of the shield placed below all the four blocks. The result is thus the travel time of the wave along $60 \mathrm{~cm}$ of marble, which leads to calculating the wave velocity without any influence from the time calibration. Following this idea, the wave velocity was measured to be $10.2 \mathrm{~cm} / \mathrm{ns}$ in the homogenous marble blocks used in this study, corresponding to a relative permittivity of 8.64 .
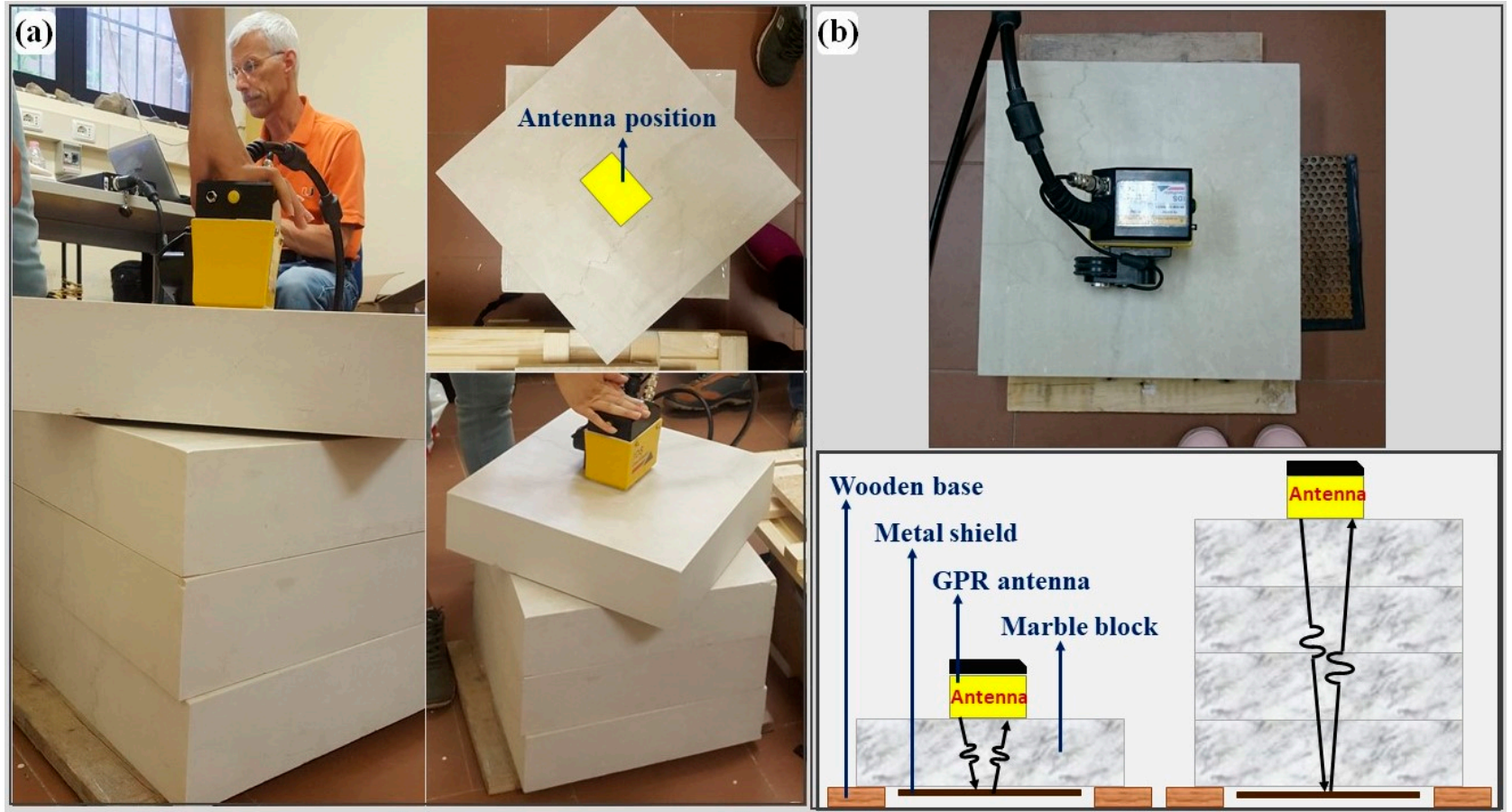

Figure 4. (a) GPR measurements in the center of marble blocks with the fracture aperture that was gradually increased from $0.25 \mathrm{~mm}$ to $16 \mathrm{~mm}$. (b) Tests using a metal shield to estimate the velocity.

After estimating the velocity, GPR measurements were performed on air-filled and repaired fractures to test GPR response to thin layers. As mentioned earlier, due to economic problems and practical limitations, only two $1 \mathrm{~mm}$-thick resin sheets were prepared. For these sheets, five measurements were performed with the following properties of the thin layer: $0 \mathrm{~mm}$ air, $1 \mathrm{~mm}$ air, $2 \mathrm{~mm}$ air, $1 \mathrm{~mm}$ resin, and $2 \mathrm{~mm}$ resin.

Regarding using the PVC sheets, a more extended range of fracture thickness could be simulated. We performed GPR tests before and after fracture repair for fracture apertures as thin as $0.25 \mathrm{~mm}$. The fracture aperture was gradually increased from $0.25 \mathrm{~mm}$ to $16 \mathrm{~mm}$. Table 1 lists the 22 measurements that were performed on air-filled fractures with 22 different apertures, and then repeated after being filled with thin layers of PVC. A total of 44 acquisitions were thus performed to compare the GPR response between the air-filled and PVC-filled fractures. 
Table 1. List of the 22 different values of the fracture apertures $(0.25-16 \mathrm{~mm})$ that were filled with PVC.

\begin{tabular}{cccccc}
\hline $\begin{array}{c}\text { Trace } \\
\text { Number }\end{array}$ & $\begin{array}{c}\text { Thickness } \\
(\mathbf{m m})\end{array}$ & $\begin{array}{c}\text { Trace } \\
\text { Number }\end{array}$ & $\begin{array}{c}\text { Thickness } \\
(\mathbf{m m})\end{array}$ & $\begin{array}{c}\text { Trace } \\
\text { Number }\end{array}$ & $\begin{array}{c}\text { Thickness } \\
(\mathbf{m m})\end{array}$ \\
\hline 1 & 0.25 & 9 & 3.5 & 17 & 11 \\
2 & 0.5 & 10 & 4 & 18 & 12 \\
3 & 0.75 & 11 & 5 & 19 & 13 \\
4 & 1 & 12 & 6 & 20 & 14 \\
5 & 1.5 & 13 & 7 & 21 & 16 \\
6 & 2 & 14 & 8 & 22 & \\
7 & 2.5 & 15 & 9 & & \\
8 & 3 & 16 & 10 & &
\end{tabular}

\subsubsection{Data Processing}

In order to determine the amplitude reflection of the thin bed, measured datasets were processed in ReflexW software, version 9.5.6, to obtain a single stack trace from each record. Time calibration and bandpass filters were applied to the data before stacking. After stacking, all the data were merged so that all the results could be visualized and compared on a single plot. Figure 5 illustrates the final results of the mentioned processing steps applied on datasets that were measured to compare the air-filled fractures (traces 1-3) with the resin-filled fractures (traces 4-5). Figure 6 shows the results for measurements on the air-filled fractures (traces 1-22) and the PVC-filled fractures (traces no. 23-44). Figures 5 and 6 were produced by applying a global normalization so that an equal gain is applied to each trace. Thus, the reflection amplitudes generated by the thin bed can be visually compared to obtain a preliminary qualitative result.

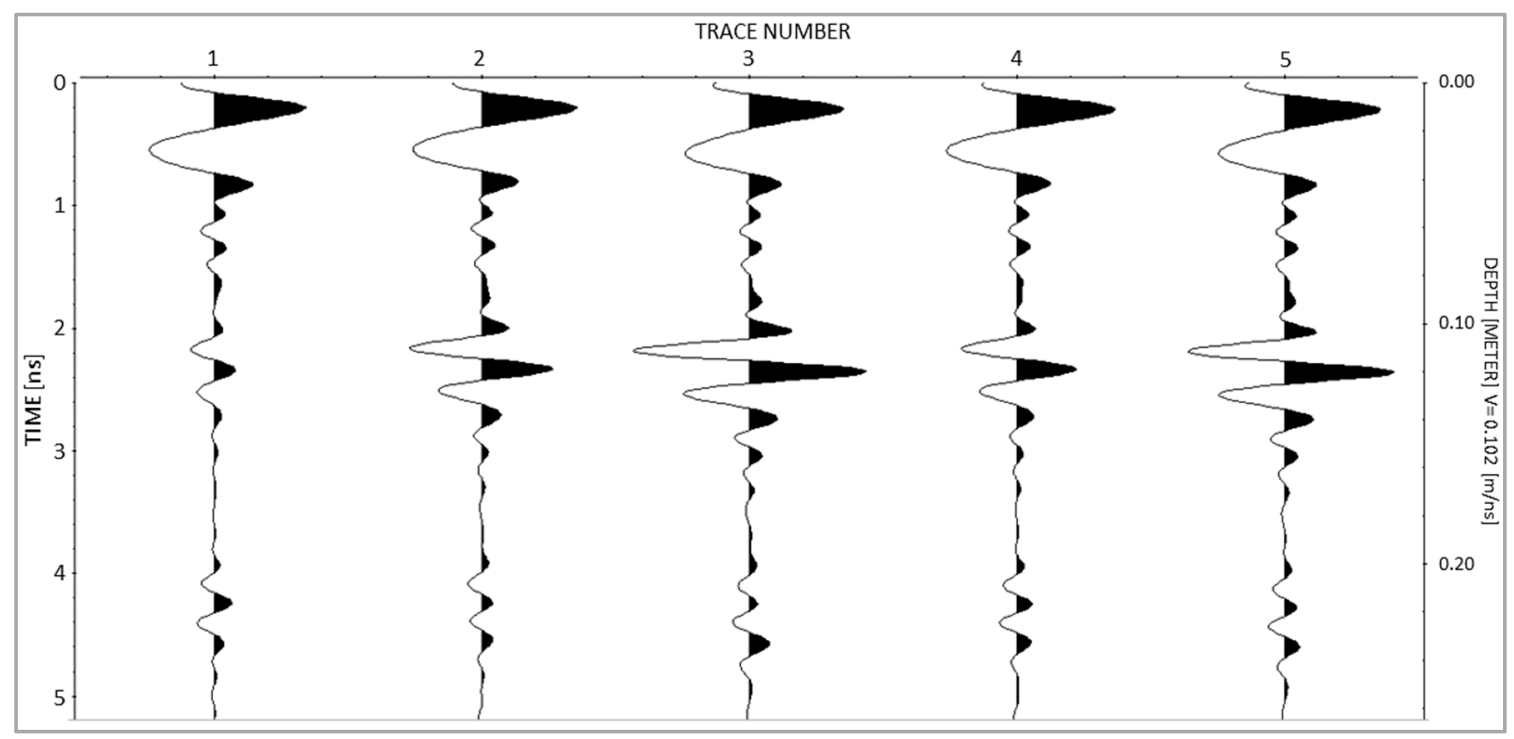

Figure 5. Data processing results for measurements on thin bed air-filled and resin-filled fractures. Note that the horizontal axis is the stacked trace number. The fracture thickness values and the filling material for these traces are: 1: $0 \mathrm{~mm}$ air, 2: $1 \mathrm{~mm}$ air, 3: $2 \mathrm{~mm}$ air, $4: 1 \mathrm{~mm}$ resin, 5: $2 \mathrm{~mm}$ resin. 


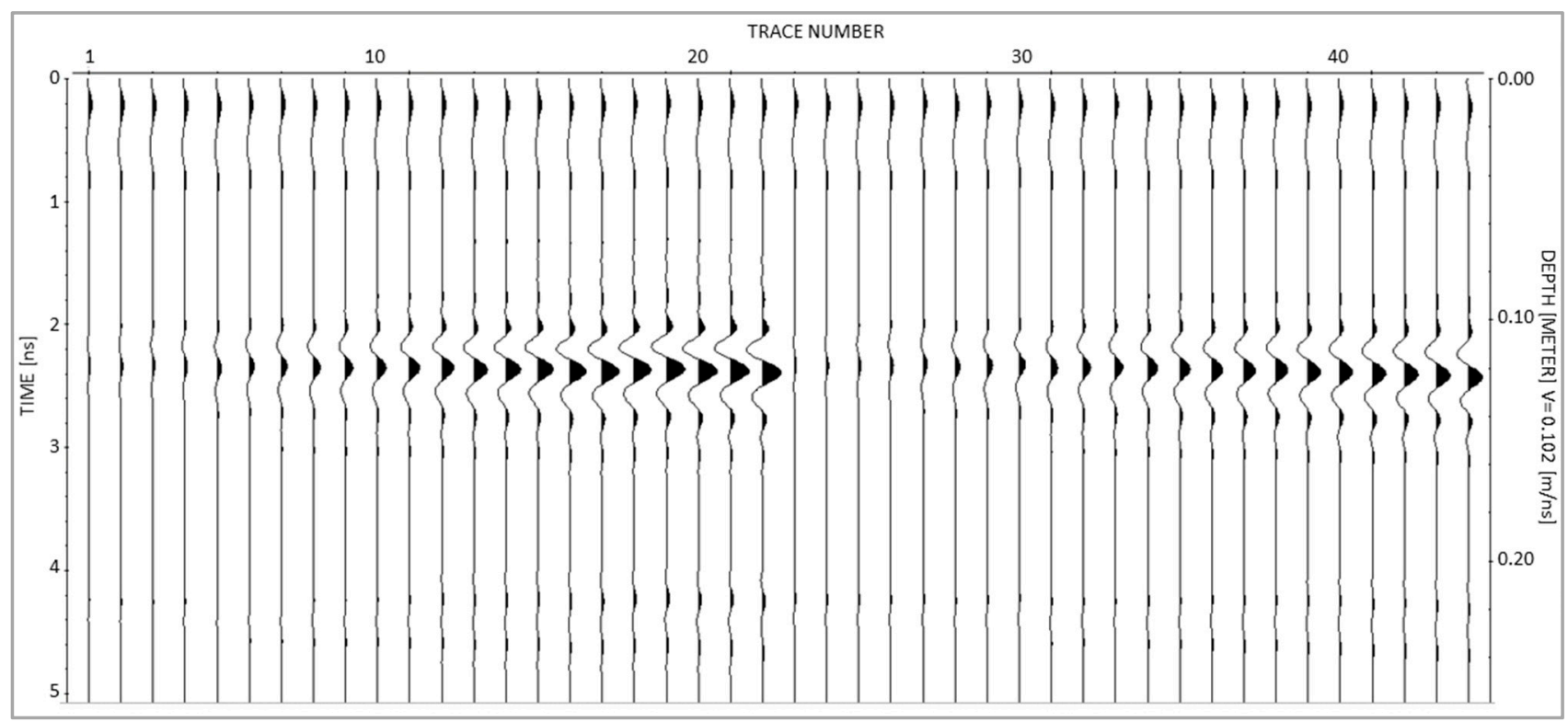

Figure 6. Data processing results for measurements on the air-filled and PVC-filled fractures with the thickness value varying from $0.25 \mathrm{~mm}$ to $16 \mathrm{~mm}$ (see Table 1). Note that the horizontal axis is the stacked trace number: 1-22 for the air-filled fractures and 23-44 for the PVC-filled fractures.

From the preview of the laboratory data, we can notice that GPR has observed the thin layer, although weakly, even with the smallest thickness. As the fracture aperture increases, the amplitude increases, and we can also appreciate slight amplitude differences at equal thickness suggesting that air-filled fractures are more reflective than resin-filled or PVC-filled fractures. These are encouraging observations, but the more substantial issue is whether these findings demonstrate that GPR can distinguish between the air-filled thin layers and the resin-filled or the PVC-filled thin layers with the sensitivity that is needed to apply the method to real blocks with unpredictable fracture geometries and thickness values. To prepare the theoretical background for interpreting the data from the laboratory test, in the next section we apply the thin bed analytical model to predict the expected amplitudes of the reflections.

\subsection{Analytical Models}

Analytical models were carried out to explore the theoretical expectations comparing GPR results before and after filling the fractures. Rock fractures can be generally considered thin beds with a distance between the two interfaces less than the resolution limit determined by Rayleigh's criterion. When a fracture in a homogeneous rock is considered a layer, it gives two signals of opposite polarity, which are reflected by the two interfaces of the fracture. If the two distinct signals are clearly identifiable and separated in time, the fracture thickness can be calculated by the time difference between the two reflections, knowing the signal velocity in the filling layer. The difference between a thin layer and a thick layer depends on the resolution of the radar system. Conventionally, the vertical resolution is estimated as a quarter of the wavelength calculated with the nominal frequency of the antenna. At $3 \mathrm{GHz}$, the theoretical expected resolution is $25 \mathrm{~mm}, 13.4 \mathrm{~mm}$, and $14.4 \mathrm{~mm}$ for the air, resin, and PVC filling material, respectively. Thus, $14 \mathrm{~mm}$ is about the maximum thickness that we can consider as a thin bed either before or after filling the fracture. When contemplating the fracture as a thin layer, the two reflections can overlap in such a way that just a single composite wavelet is identifiable, and this interference may be constructive or destructive. The response of the thin layer is the sum of the primary reflections and multiple reflections that occur within the layer $[46,54,55]$. Therefore, the reflection coefficient is affected by the properties of the thin bed (i.e., thickness and filling material) because it is related to the permittivity contrast between the rock and the filling 
material as well as to the ratio of the bed thickness to the wavelength within the thin bed. The value of the reflection coefficient changes linearly with the thin bed thickness for layers much thinner than the wavelength. The magnitude of the reflection coefficient oscillates between zero and a maximal value as the layer becomes thicker, depending on the destructive or constructive interference between the primary and multiple reflections [46]. This behavior can be analytically predicted using the following equation [46]:

$$
|\Gamma|=\left|\frac{2 R_{12} \sin (2 \pi d / \lambda)}{\sqrt{\left(1-R_{12}^{2}\right)^{2}+\left(2 R_{12} \sin (2 \pi d / \lambda)\right)^{2}}}\right|
$$

where $\Gamma$ is the thin bed reflection coefficient, $R_{12}$ is the normal incidence electromagnetic reflection coefficient between mediums 1 and 2 (rock and filling material, respectively), and $\lambda$ is the pulse wavelength inside the thin bed. The following equation is used to calculate $R_{12}$ :

$$
R_{12}=\frac{\sqrt{\varepsilon_{1}}-\sqrt{\varepsilon_{2}}}{\sqrt{\varepsilon_{1}}+\sqrt{\varepsilon_{2}}}
$$

where $\varepsilon_{1}$ and $\varepsilon_{2}$ are, respectively, the permittivity of medium 1 and medium 2 . We used Equation (2) to predict the theoretical behavior of the air-filled, resin-filled, and PVC-filled thin beds.

Figure 7 indicates the predicted theoretical difference between the air-filled and the resin-filled fractures. Although only two thicknesses of $1 \mathrm{~mm}$ and $2 \mathrm{~mm}$ were tested in the laboratory measurements with resin layers, a wide thickness range $(0-40 \mathrm{~mm})$ is plotted here in order to explore the trend of the reflection coefficient variations. The results illustrate that a 33\% difference between the air-filled and the resin-filled fractures is expected for the smallest fracture apertures. The percentage difference theoretically increases to $100 \%$ when the fracture thickness is equal to half the wavelength calculated within the resin. Therefore, if GPR detects a thin bed fracture before resin injection, a minimum of $33 \%$ amplitude reduction can be expected after resin injection.
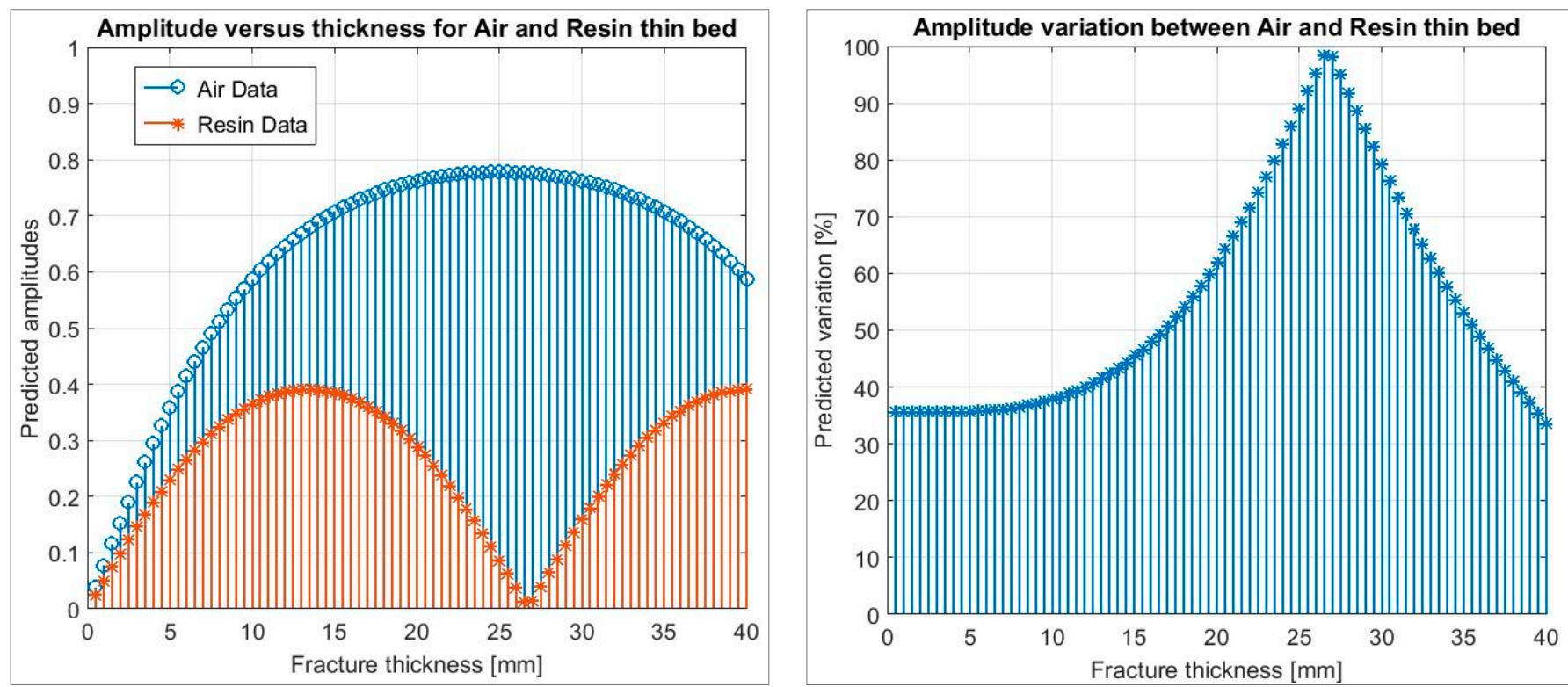

Figure 7. Comparison of the predicted amplitudes for the air-filled fractures versus the resin-filled fractures with a $3 \mathrm{GHz}$ antenna. Circles: air data, Stars: resin data.

Similarly, Figure 8 shows the predicted theoretical disparity between the air-filled and the PVC-filled fractures. The comparison was limited to the thin bed range of the laboratory tests, i.e., from $0.25 \mathrm{~mm}$ to $16 \mathrm{~mm}$. The qualitative trend for larger fractures 
would be the same as observed in Figure 7 . The findings show that a $26 \%$ difference between the air-filled and the PVC-filled fractures is expected even for the smallest fracture apertures. The percentage difference then gently increases to $35 \%$ when approaching the $16 \mathrm{~mm}$ thickness.
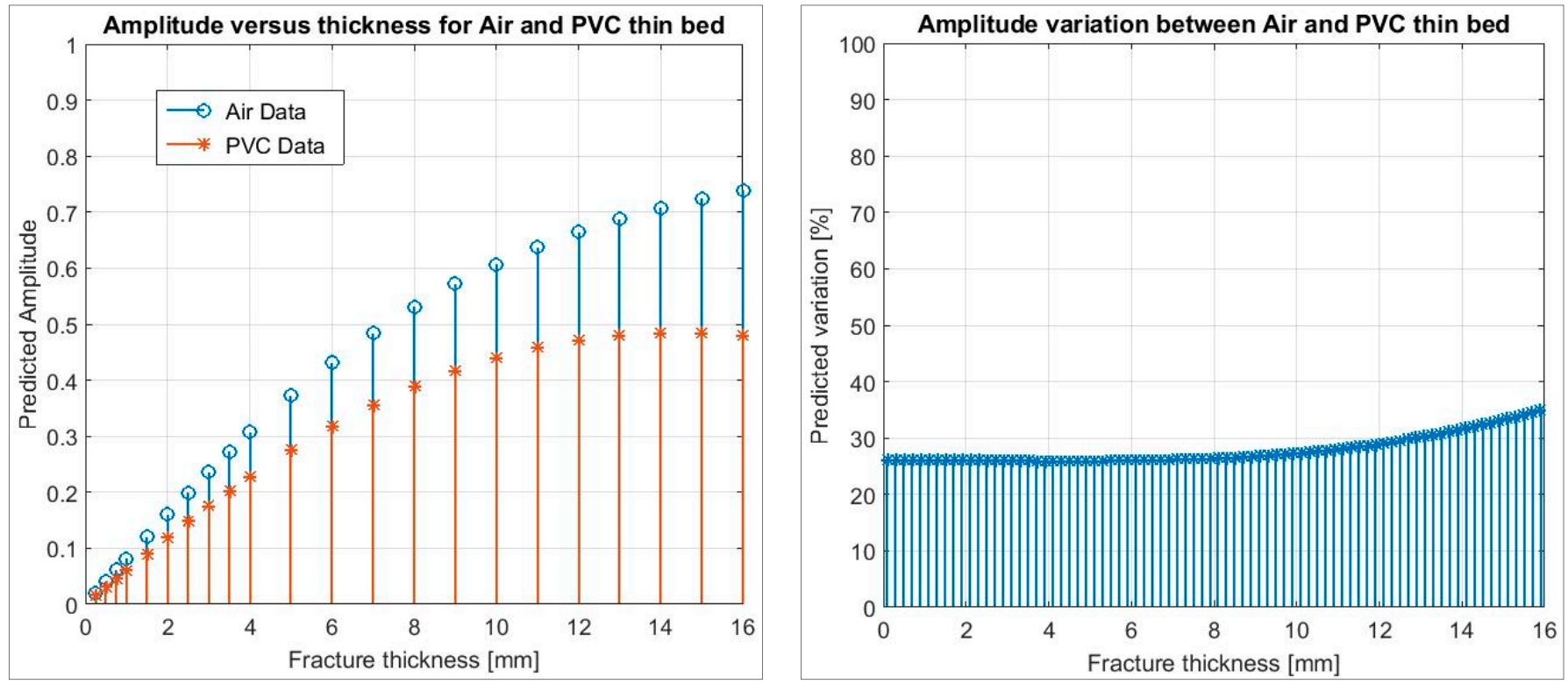

Figure 8. Comparing the predicted amplitudes for the air-filled fractures versus the PVC-filled fractures with a $3 \mathrm{GHz}$ antenna. Circles: air data, stars: PVC data.

\section{Results and Discussion}

The laboratory data were processed by using the ReflexW software, but the amplitude picking was performed manually. To prevent the influence of any DC or very low frequency components on the amplitude values, we decided to analyze the peak-to-peak amplitudes (sum of positive and negative peaks) of the reflected waves. We did not make any amplitude compensation for possible variations of the power radiated by the TX antenna during the measurements since the antenna was properly warmed up before the measurements, and the time needed to collect all the data, before and after filling the fracture, was short enough to assume that the radiated power could not be affected by drift phenomena induced by battery discharge.

GPR findings before and after filling the thin layer with resin are shown in Table 2. A $33 \%$ amplitude difference between the air-filled and the resin-filled fracture was predicted based on the thin bed analytical model (Figure 7). An amplitude decrease is confirmed by the real data, but the intensity of the amplitude variation is less remarkable, although high enough to be observed on the real data.

Table 2. Variations in the peak-to-peak amplitudes of the air-filled and resin-filled layers between marble blocks.

\begin{tabular}{cc}
\hline Fracture Thickness $(\mathbf{m m})$ & Difference in the Peak-to-Peak Amplitude (\%) \\
\hline 1 & 20.0 \\
2 & 12.1 \\
\hline
\end{tabular}

These findings indicate that GPR can detect the change in the filling material at these thickness values, i.e., it can be used to perform a quality check of the resin injection. However, the accuracy is not high enough to use the amplitude variations to estimate the permittivity of the filling material, i.e., to identify the filling material. Since the amplitude decrease observed in the results of laboratory measurements is lower than the prediction, 
the permittivity of the filling material would be underestimated. Nevertheless, the quantitative interpretation of the amplitude variations is beyond the objectives of this work. Our assumption is that we know the injected material and what we need to control with a nondestructive method is only its diffusion within the injected fractures.

The results of the laboratory tests where PVC was used as a substitute of the resin are shown in Figure 9. The plots compare the expected theoretical trend with the observed amplitude trend for the air-filled fractures (left) and the PVC-filled fractures (right). The graphs of the real amplitudes have been properly rescaled before plotting to fit the theoretical values of the reflection coefficient calculated at the thickness of $16 \mathrm{~mm}$. We observe an encouraging similarity between the theoretical and the experimental trends. It is also encouraging to observe that it was possible to pick the amplitudes of the thin bed reflections even when the fracture thickness is very small $(0.25 \mathrm{~mm})$.
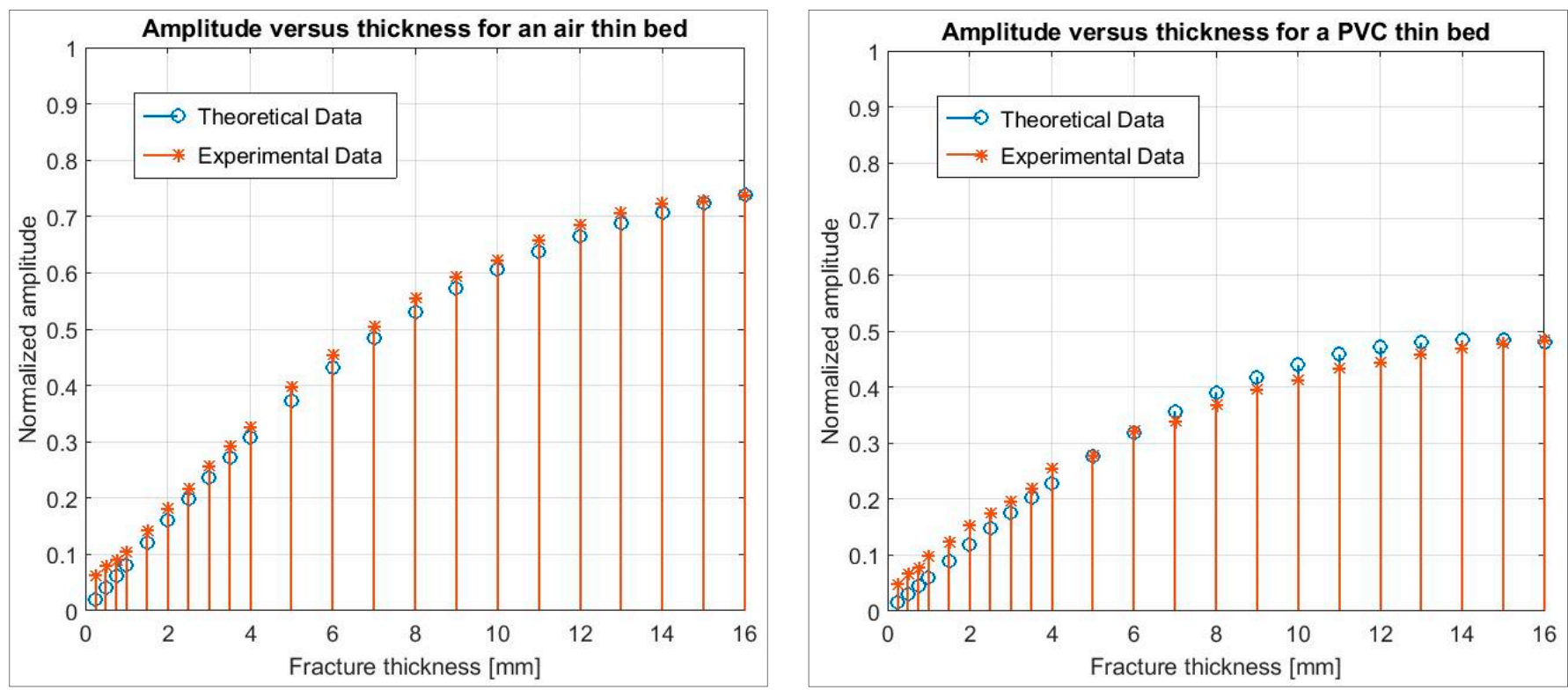

Figure 9. Amplitude versus thickness for the air-filled fractures (left) and the PVC-filled fractures (right). Stars are peak-to-peak amplitudes from laboratory tests, after rescaling. Circles are reflection coefficients calculated from the thin bed theory (Equation (1)).

Figure 10 illustrates the quantitative comparison of the percentual amplitude variations as predicted from the thin bed theory and as observed experimentally.

For most thicknesses, the observed values are very similar to the values predicted by the thin bed theory. More specifically, we can notice that the final trend of the theoretical plot that is progressively increasing, arriving at $35 \%$ for $16 \mathrm{~mm}$, is not perfectly matched by the real data that start to deviate from this trend when the thickness overcomes $13 \mathrm{~mm}$. However, this is consistent with the theory, because according to the resolution limit determined by Rayleigh's criterion mentioned in Section 2.3, the maximum thickness that we can consider as a thin bed after filling the layer is about $14 \mathrm{~mm}$. Thus, the theoretical predictions become questionable for thickness values larger than $14 \mathrm{~mm}$. On the other hand, we also notice that real data severely deviate from the theoretical predictions when the thickness is smaller than $4 \mathrm{~mm}$. This seems to suggest the following statement as a general conclusion: although fractures can be detected at any thickness in the explored range (from $0.25 \mathrm{~mm}$ to $16 \mathrm{~mm}$ ), it seems that the accuracy of the amplitude measurements with the $3 \mathrm{GHz}$ antenna is not good enough to make a quantitative characterization of the filling material when the thickness is less than $4 \mathrm{~mm}$. Again, the mismatch between the real data and the predictions is underestimating the expected amplitude variations and this would result in underestimating the permittivity of the filling material. This underestimation is consistent with what was observed in the comparison of the air-filled fractures with the 
resin-filled fractures, and it seems to suggest that the problem persists up to thickness values of about $4 \mathrm{~mm}$. For fractures with an aperture larger than $4 \mathrm{~mm}$ and up to the maximum thickness that can be modeled as a thin bed, the amplitude variation is so close to the predicted results that a quantitative characterization of the filling material becomes quite reliable. However, returning to our specific application where the objective of the GPR survey is to detect the change in the filling material, i.e., to perform quality control of the propagation of the injected material within the fracture, we can conclude that the method is successful for any tested thickness, thus validating the methodology on a wide range of fracture apertures (from $0.25 \mathrm{~mm}$ to $16 \mathrm{~mm}$ ).

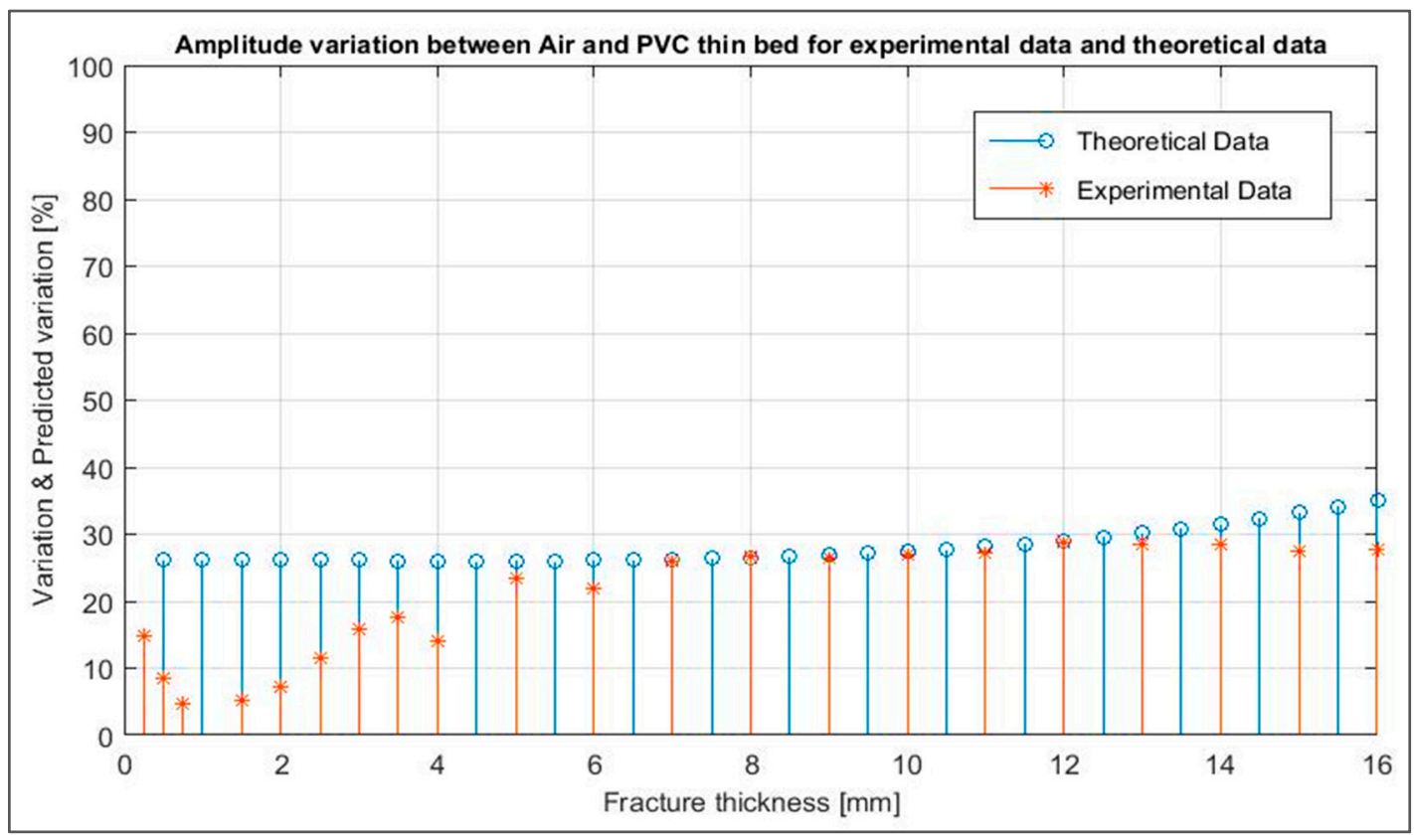

Figure 10. Comparing the amplitude difference between the air-filled and the PVC-filled fractures obtained from theoretical models (circles) and laboratory measurements (stars).

Going back to Figure 9, we can easily explain the deviation between the theoretical predictions and experimental observations when the fracture thickness becomes very small. For very thin fractures, the reflection coefficients are very small and the reflected GPR waves are so weak (Figure 8) that the picking becomes more sensitive to the noise, resulting in less accurate amplitudes.

From Figure 9, we can also observe that for very thin fractures, amplitudes are more sensitive to thickness variations, i.e., the derivative of the amplitude versus thickness graph is larger than elsewhere. From this comment, we can derive an important recommendation for a successful use of GPR to perform the quality control of resin injections. If GPR measurements after resin injections are not exactly repeated at the same locations of the measurements performed before injections, the observed amplitude variations might be generated not only by injections but also by thickness differences at the two different locations. Thus, erroneous conclusions might result from the quality control especially where the observed fractures are particularly thin.

\section{Conclusions}

Epoxy resin is widely used to repair the fractures of building and decorative stones. In this study, we considered the thin layer between two marble blocks as a fracture in a homogenous rock to analyze the potential of the GPR method to perform nondestructive quality control of resin injections. Since the resin adheres strongly to the stone after injection, we used dried filling layers to be able to change the fracture thickness during testing. By progressively increasing the thin layer thickness from $0.25 \mathrm{~mm}$ to $16 \mathrm{~mm}$, we tested the 
GPR response at $3 \mathrm{GHz}$ before and after injections, where the after-injections situation was simulated by filling the thin layer with PVC sheets, the permittivity of PVC being very similar to the permittivity of epoxy resin. The GPR response before and after injections was also quantitatively compared with the theoretical predictions based on the analytical model of the thin bed reflection.

Except for very thin fractures (thickness values smaller than $4 \mathrm{~mm}$ ), experimental measurements fit very well the theoretical predictions up to the maximum thickness that can be modeled as a thin bed (about $14 \mathrm{~mm}$ at $3 \mathrm{GHz}$ for a resin-injected fracture), equal to the resolution limit determined by Rayleigh's criterion. Although some deviations from the theory are observed with very thin fractures, the experimental amplitude variations are always qualitatively consistent with the predictions and large enough to be detected. Based on these results, this study validates the GPR method as a proper tool for quality control of resin injections in marble fractures of any thickness in the tested range $(0.25-16 \mathrm{~mm})$. For the thickness range where experimental data fully match the theoretical predictions, the potential of the GPR methodology is even higher, being able to characterize the injected material. However, the characterization of the injected material is beyond the scope of this work which is focused on validating the GPR as a tool for controlling the successful diffusion of the resin within the repaired fractures. An important recommendation that descends from this study is that GPR tests before and after injections must be accurately repeated at the same locations to prevent ambiguities between the amplitude effects induced by the injections and the amplitude effects induced by the thickness variations due to wrong positioning of the antenna. The recommendation is particularly relevant when the fractures are very thin because GPR amplitudes are extremely sensitive to thickness variations in that range of thickness values. Finally, a further recommendation is necessary considering that GPR tests before and after the resin injections cannot be performed in a short time interval as we did in our laboratory simulations, where resin injections were simulated with wafers made with PVC sheets. As a result, it is recommended to conduct all the measurements when the battery is fully charged, to wait for a proper warm-up of the antenna before starting the measurements and to perform a prudential calibration test on a proper specimen of the power radiated by the TX antenna at the beginning and at the end of every measurement session. The goal is to ensure that the received amplitudes are only affected by changing the filling material and they are not affected by any other factor (e.g., temperature, battery level, other environmental conditions), and in case of unwanted variations of the external conditions, to have calibration tests for estimating and applying the proper amplitude corrections.

Author Contributions: Conceptualization, A.H. and L.Z.; methodology, M.I.-Y., A.H., L.Z. and S.K.-N.; software, M.I.-Y., A.H. and L.Z.; investigation, M.I.-Y., A.H., L.Z., S.K.-N. and D.A.; data curation, M.I.-Y., A.H. and L.Z.; writing—original draft preparation, M.I.-Y., A.H. and L.Z.; writing—review and editing, M.I.-Y., A.H., L.Z., S.K.-N. and D.A.; visualization, A.H. and L.Z.; supervision, A.H. and L.Z.; funding acquisition, M.I.-Y. and L.Z. All authors have read and agreed to the published version of the manuscript.

Funding: Laboratory and data processing studies of this research were performed at Politecnico di Milano, Italy, during January-August 2019 for the visiting PhD student Marjan Izadi Yazdanabadi whose visit in Italy was financially supported by the Iranian Ministry of Science Research and Technology.

Data Availability Statement: Datasets used in this research will be sent to interested researchers upon request.

Acknowledgments: The authors are grateful to Eng. Rita Alberti for generously providing marble blocks of this study quarried by Terreni and Coa S.r.l.

Conflicts of Interest: The authors declare no conflict of interest. 


\section{References}

1. Anzani, A.; Binda, L.; Lualdi, M.; Tedeschi, C.; Zanzi, L. Use of sonic and GPR tests to control the effectiveness of grout injections of stone masonry. In Proceedings of the 9th European Conference on NDT, Berlin, Germany, 25-29 September 2006; pp. 1-7.

2. López-Buendía, A.M.; Guillem, C.; Cuevas, J.M.; Mateos, F.; Montoto, M. Natural stone reinforcement of discontinuities with resin for industrial processing. Eng. Geol. 2013, 166, 39-51. [CrossRef]

3. Clifton, J.R. Stone Consolidating Materials: A Status Report; Department of Commerce, National Bureau of Standards: Washington, DC, USA, 1980; Volume 1118, pp. 15-30.

4. Selwitz, C. The use of epoxy resins for stone consolidation. In Proceedings of the Material Issues in Art \& Archeology II, San Francisco, CA, USA, 17-21 April 1990; pp. 181-191. [CrossRef]

5. Doehne, E.; Price, C.A. Stone Conservation: An Overview of Current Research, 2nd ed.; The Getty Conservation Institute: Los Angeles, CA, USA, 2010; pp. 27-43.

6. Tesser, E.; Lazzarini, L.; Bracci, S. Investigation on the chemical structure and ageing transformations of the cycloaliphatic epoxy resin EP2101 used as stone consolidant. J. Cult. Herit. 2018, 31, 72-82. [CrossRef]

7. Capizzi, P.; Cosentino, P.L. Electromagnetic and ultrasonic investigations on a Roman marble slab. J. Geophys. Eng. 2011, 8, S117-S125. [CrossRef]

8. Karimi Nasab, S.; Hojat, A.; Kamkar-Rouhani, A.; Akbari Javar, H.; Maknooni, S. Successful use of geoelectrical surveys in Area 3 of the Gol-e-Gohar iron ore mine, Iran. Mine Water Environ. 2011, 30, 208-215. [CrossRef]

9. Malehmir, A.; Durrheim, R.; Bellefleur, G.; Urosevic, M.; Juhlin, C.; White, D.J.; Milkereit, B.; Campbell, G. Seismic methods in mineral exploration and mine planning: A general overview of past and present case histories and a look into the future. Geophysics 2012, 77, WC173-WC190. [CrossRef]

10. Malehmir, A.; Tryggvason, A.; Wijns, C.; Koivisto, E.; Lindqvist, T.; Skyttä, P.; Montonen, M. Why 3D seismic data are an asset for exploration and mine planning? Velocity tomography of weakness zones in the Kevitsa Ni-Cu-PGE mine, northern Finland. Geophysics 2018, 83, B33-B46. [CrossRef]

11. Apostolopoulos, G.; Menegaki, M.; Amolochitis, G.; Karaiskos, D. Geophysical methods to improve productivity of a marble quarry. In Proceedings of the Near Surface Geoscience 2016-First Conference on Geophysics for Mineral Exploration and Mining, Barcelona, Spain, 4-8 September 2016; pp. 1-5. [CrossRef]

12. Moradipour, M.; Ranjbar, H.; Hojat, A.; Karimi Nasab, S.; Daneshpajouh, S. Laboratory and field measurements of electrical resistivity to study heap leaching pad No. 3 at Sarcheshmeh copper mine. In Proceedings of the Near Surface Geoscience 2016-22nd European Meeting of Environmental and Engineering Geophysics, Barcelona, Spain, 4-8 September 2016; pp. 1-5. [CrossRef]

13. Martínez, J.; Montiel, V.; Rey, J.; Cañadas, F.; Vera, P. Utilization of integrated geophysical techniques to delineate the extraction of mining bench of ornamental rocks (marble). Remote Sens. 2017, 9, 1322. [CrossRef]

14. Dentith, M.; Yuan, H.; Johnson, S.; Murdie, R.; Pina-Varas, P. Application of deep-penetrating geophysical methods to mineral exploration: Examples from Western Australia. Geophysics 2018, 83, WC29-WC41. [CrossRef]

15. Uhlemann, S.; Chambers, J.; Falck, W.E.; Tirado Alonso, A.; Fernández González, J.L.; Espín de Gea, A. Applying electrical resistivity tomography in ornamental stone mining: Challenges and solutions. Minerals 2018, 8, 491. [CrossRef]

16. Targa, D.A.; Moreira, C.A.; Camarero, P.L.; Casagrande, M.F.S.; Alberti, H.L.C. Structural analysis and geophysical survey for hydrogeological diagnosis in uranium mine, Poços de Caldas (Brazil). SN Appl. Sci. 2019, 1, 299. [CrossRef]

17. Tresoldi, G.; Hojat, A.; Zanzi, L. G.RE.T.A. installations for real-time monitoring of irrigation dams and canals. Procedia Environ. Sci. Eng. Manag. 2020, 7, 271-276.

18. Porzucek, S.; Loj, M. Microgravity survey to detect voids and loosening zones in the vicinity of the mine shaft. Energies 2021, 14, 3021. [CrossRef]

19. Valle, S.; Zanzi, L. Traveltime radar tomography for NDT on masonry and concrete structures. Eur. J. Environ. Eng. Geophys. 1998, 2, 229-246.

20. Maierhofer, C.; Leipold, S. Radar investigation of masonry structures. NDT E Int. 2001, 34, 139-147. [CrossRef]

21. Binda, L.; Lualdi, M.; Saisi, A.; Zanzi, L. Radar investigation as a complementary tool for the diagnosis of historic masonry buildings. Int. J. Mater. Struct. Integr. 2011, 5, 1-25. [CrossRef]

22. Dojack, L. Ground Penetrating Radar Theory, Data Collection, Processing, and Interpretation: A Guide for Archaeologists. Ph.D. Thesis, University of British Columbia, Vancouver, BC, Canada, 2012; 89p. [CrossRef]

23. Conyers, L.B. Ground-Penetrating Radar for Archaeology, 3rd ed.; AltaMira Press: Lenham, MD, USA, 2013 ; pp. $12-17$.

24. Xiang, L.; Zhou, H.; Shu, Z.; Tan, S.; Liang, G.; Zhu, J. GPR evaluation of the Damaoshan highway tunnel: A case study. NDT E Int. 2013, 59, 68-76. [CrossRef]

25. Benedetto, A.; Tosti, F.; Ciampoli, L.B.; D'amico, F. An overview of ground-penetrating radar signal processing techniques for road inspections. Signal Process. 2017, 132, 201-209. [CrossRef]

26. Hojat, A.; Zanzi, L.; Loke, M.H.; Ranjbar, H.; Karimi-Nasab, S. Integration of geoengineering techniques to map hidden qanats at Shahid Bahonar University of Kerman. In Proceedings of the 24th European Meeting of Environmental and Engineering Geophysics, Porto, Portugal, 9-12 September 2018; pp. 1-5. [CrossRef] 
27. Hojat, A.; Zanzi, L.; Karimi-Nasab, S.; Ranjbar, H.; Loke, M.H. Laboratory and field GPR measurements to detect qanats. In Proceedings of the 10th International Workshop on Advanced Ground Penetrating Radar, The Hague, The Netherlands, 8-12 September 2019; pp. 1-5. [CrossRef]

28. Arosio, D.; Hojat, A.; Munda, S.; Zanzi, L. High-frequency GPR investigations in Saint Vigilius Cathedral, Trento. In Proceedings of the 24th European Meeting of Environmental and Engineering Geophysics, Porto, Portugal, 9-12 September 2018; pp. 1-5. [CrossRef]

29. Arosio, D.; Hojat, A.; Munda, S.; Zanzi, L. Non-destructive root mapping: Exploring the potential of GPR. In Proceedings of the 3rd Asia Pacific Meeting on Near Surface Geoscience \& Engineering, Chiang Mai, Thailand, 2-5 November 2020; pp. 1-5. [CrossRef]

30. Gustavsen, L.; Stamnes, A.A.; Fretheim, S.E.; Gjerpe, L.E.; Nau, E. The effectiveness of large-scale, high-resolution groundpenetrating radar surveys and trial trenching for archaeological site evaluations-A comparative study from two sites in Norway. Remote Sens. 2020, 12, 1408. [CrossRef]

31. Economou, N.; Bano, M.; Ortega-Ramirez, J. Delineation of fractures using a 2D GPR processing strategy for 3D imaging: Weak zones within Carbonates at the archaeological site of Xochicalco in Mexico. Appl. Sci. 2021, 11, 5893. [CrossRef]

32. Klewe, T.; Strangfeld, C.; Ritzer, T.; Kruschwitz, S. Combining signal features of ground-penetrating radar to classify moisture damage in layered building floors. Appl. Sci. 2021, 11, 8820. [CrossRef]

33. Negri, S.; Aiello, M.A. High-resolution GPR survey for masonry wall diagnostics. J. Build. Eng. 2021, 33, 101817. [CrossRef]

34. Grandjean, G.; Gourry, J.-C. GPR data processing for 3D fracture mapping in a marble quarry (Thassos, Greece). J. Appl. Geophys. 1996, 36, 19-30. [CrossRef]

35. Lualdi, M.; Zanzi, L. 2D and 3D GPR imaging to map the fractures and to evaluate the integrity of limestone ornamental rocks. In Proceedings of the Symposium on the Application of Geophysics to Engineering and Environmental Problems, San Antonio, TX, USA, 6-10 April 2003; pp. 613-622.

36. Lualdi, M.; Zanzi, L. 2D and 3D experiments to explore the potential benefit of GPR investigations in planning the mining activity of a limestone quarry. In Proceedings of the 10th International Conference on Ground Penetrating Radar, Delft, The Netherlands, 21-24 June 2004; pp. 613-616.

37. Porsani, J.L.; Sauck, W.A.; Júnior, A.O. GPR for mapping fractures and as a guide for the extraction of ornamental granite from a quarry: A case study from southern Brazil. J. Appl. Geophys. 2006, 58, 177-187. [CrossRef]

38. Kadioglu, S. Photographing layer thicknesses and discontinuities in a marble quarry with 3D GPR visualisation. J. Appl. Geophys. 2008, 64, 109-114. [CrossRef]

39. Arosio, D.; Munda, S.; Zanzi, L. Quality control of stone blocks during quarrying activities. In Proceedings of the 201214 th International Conference on Ground Penetrating Radar (GPR), Shanghai, China, 4-8 June 2012; pp. 822-826. [CrossRef]

40. Arosio, D.; Zanzi, L.; Longoni, L.; Papini, M. Fracture thickness from GPR measurements. In Proceedings of the 8th International Workshop on Advanced Ground Penetrating Radar (IWAGPR), Florence, Italy, 7-10 July 2015; pp. 1-4. [CrossRef]

41. Rey, J.; Martínez, J.; Vera, P.; Ruiz, N.; Cañadas, F.; Montiel, V. Ground-penetrating radar method used for the characterisation of ornamental stone quarries. Constr. Build. Mater. 2015, 77, 439-447. [CrossRef]

42. Hojat, A.; Izadi-Yazdanabadi, M.; Karimi-Nasab, S.; Arosio, D.; Zanzi, L. GPR method as an efficient NDT tool to characterize carbonate rocks during different production stages. In Proceedings of the EAGE-GSM 2nd Asia Pacific Meeting on Near Surface Geoscience and Engineering, Kuala Lumpur, Malaysia, 24-25 April 2019; pp. 1-5. [CrossRef]

43. Zanzi, L.; Hojat, A.; Ranjbar, H.; Karimi-Nasab, S.; Azadi, A.; Arosio, D. GPR measurements to detect major discontinuities at Cheshmeh-Shirdoosh limestone quarry, Iran. Bull. Eng. Geol. Environ. 2019, 78, 743-752. [CrossRef]

44. Sambuelli, L.; Calzoni, C. Estimation of thin fracture aperture in a marble block by GPR sounding. Boll. Geof. Teor. Appl. 2010, 51, 239-252.

45. Markovaara-koivisto, M.; Hokkanen, T.; Huuskonen-Snicker, E. The effect of fracture aperture and filling material on GPR signal. Bull. Eng. Geol. Environ. 2014, 73, 815-823. [CrossRef]

46. Arosio, D. Rock fracture characterization with GPR by means of deterministic deconvolution. J. Appl. Geophys. 2016, 126, 27-34. [CrossRef]

47. Annan, A.P. Ground Penetrating Radar Workshop Notes; Sensors \& Software Inc.: Mississauga, ON, Canada, 2001; 192p.

48. IDS GeoRadar. Available online: https://idsgeoradar.com/products/ground-penetrating-radar (accessed on 12 January 2022).

49. TERRENI \& COA s.r.l. Available online: http://terreniecoa.it/en/quarries/ (accessed on 3 May 2019).

50. ResinPro. Available online: https://resinpro.eu/product/transparent-epoxy-resin-from-gr-800/ (accessed on 30 March 2019).

51. Pitt, C.; Barth, B.; Godard, B. Electrical properties of epoxy resins. IRE Trans. Compon. Parts 1957, 4, 110-113. [CrossRef]

52. Johari, G.P. Electrical properties of epoxy resins. In Chemistry and Technology of Epoxy Resins; Springer: Dordrecht, The Netherlands, 1993; pp. 175-205.

53. Matzui, L.Y.; Vovchenko, L.L.; Perets, Y.S.; Lazarenko, O.A. Electrical conductivity of epoxy resin filled with graphite nanoplatelets and boron nitride. Materialwissenschaft und Werkstofftechnik 2013, 44, 254-258. [CrossRef]

54. Jol, H.M. Ground Penetrating Radar Theory and Applications; Elsevier: Amsterdam, The Netherlands, 2008; 544p.

55. Deparis, J.; Garambois, S. On the use of dispersive APVO GPR curves for thin-bed properties estimation: Theory and application to fracture characterization. Geophysics 2009, 74, J1-J12. [CrossRef] 